\title{
Uncovering the relationship between subducting bathymetric ridges and volcanic chains with significant earthquakes using geophysical data mining
}

\author{
T. C. W. LANDGREBE AND R. D. MÜLLER
}

EarthByte Group, School of Geosciences, Madsen Building, The University of Sydney, NSW 2006, Australia.

E-mail: dietmar.muller@sydney.edu.au,

Tel: +61 29351 3625, Fax +61293512442

\section{SUPPLEMENTARY PAPERS}

Australian Journal of Earth Sciences (2015) 62,

http://dx.doi.org/10.1080/08120099.2015.1003145

Copies of Supplementary Papers may be obtained from the Geological Society of Australia's website (www.gsa.org.au), the Australian Journal of Earth Sciences website (www.ajes.com.au) or from the National Library of Australia's Pandora archive (http://nla.gov.au/nla.arc-25194).

\section{SUPPLEMENTARY PAPERS}

Table A.1 Latitude-longitude pairs pertaining to identified fracture-zone intersections with subduction zones.

Table A.2 Latitude-longitude pairs pertaining to identified volcanic ridge/seamountchain intersections with subduction zones 


\section{APPENDIX}

Table A.1 Latitude-longitude pairs pertaining to identified fracture-zone intersections with subduction zones.

$\begin{array}{cccccc}\text { Latitude } & \text { Longitude } & \text { Latitude } & \text { Longitude } & \text { Latitude } & \text { Longitude } \\ -2.277 & 98.529 & -4.194 & -81.977 & 36.193 & 142.769 \\ 3.829 & 93.172 & -4.499 & -82.009 & 35.871 & 142.529 \\ 7.75 & 91.882 & -5.103 & -82.001 & 51.336 & 160.426 \\ 2.346 & 94.585 & -5.361 & -81.992 & 53.299 & 162.616 \\ 2.615 & 94.231 & -10.087 & -80.272 & -37.94 & -74.634 \\ -7.972 & 104.055 & -8.989 & -80.898 & -61.481 & -61.098 \\ -7.426 & 102.846 & -10.398 & -80.091 & -56.746 & -69.786 \\ -6.792 & 102.075 & 15.218 & -95.694 & -61.324 & -60.48 \\ -3.092 & 99.202 & 13.383 & -92.463 & 23.667 & 126.257 \\ -7.215 & 102.483 & -17.632 & -73.569 & 23.91 & 126.634 \\ 1.757 & 95.715 & -45.619 & -75.997 & -32.408 & -72.789 \\ 17.003 & -59.192 & -45.834 & -75.995 & 50.751 & 177.422 \\ 13.205 & -57.587 & -46.604 & -75.969 & 51.023 & -172.852 \\ 12.942 & -57.544 & -47.015 & -75.993 & 50.525 & -176.819 \\ 13.559 & -57.652 & -48.943 & -76.988 & -59.295 & -24.365 \\ 13.887 & -57.712 & -43.892 & -75.723 & -58.21 & -23.823 \\ 55.836 & -152.693 & -41.767 & -75.396 & -57.217 & -24.215 \\ 56.249 & -151.462 & -40.334 & -75.192 & 8.58 & -82.61 \\ 14.891 & -95.124 & -40.024 & -75.154 & 40.3 & -124.73 \\ -3.047 & -81.642 & 42.641 & 147.255 & & \end{array}$

Table A.2 Latitude-longitude pairs pertaining to identified volcanic ridge/seamountchain intersections with subduction zones.

$\begin{array}{cccc}\text { Latitude } & \text { Longitude } & \text { Latitude } & \text { Longitude } \\ -0.79 & -81.54 & -11.28 & 115.06 \\ 7.89 & -83.36 & -6.53 & 154.21 \\ 15.87 & 147.76 & -25.19 & -175.24 \\ 20.37 & 147.19 & -35.8 & -179.13 \\ 24.39 & 143.48 & -40.64 & 178.5 \\ 54.11 & 163.1 & -9.65 & 158.94 \\ -15.27 & -76.45 & 10.85 & 139.52\end{array}$

